\title{
Use of the ARM Measurements of Spectral Zenith Radiance for Better Understanding of 3D Cloud-Radiation Processes and Aerosol-Cloud Interaction
}

\author{
Jui-Yuan Chiu \\ Award \#: DOE DE-FG02-08ER64563
}

\section{Project goals}

Our proposal focuses on cloud-radiation processes in a general 3D cloud situation, with particular emphasis on cloud optical depth and effective particle size. We also focus on zenith radiance measurements, both active and passive. The proposal has three main parts.

Part One exploits the "solar-background" mode of ARM lidars to allow them to retrieve cloud optical depth not just for thin clouds but for all clouds. This also enables the study of aerosolcloud interactions with a single instrument.

Part Two exploits the large number of new wavelengths offered by ARM's zenith-pointing ShortWave Spectrometer (SWS), especially during CLASIC, to develop better retrievals not only of cloud optical depth but also of cloud particle size. We also propose to take advantage of the SWS' $1 \mathrm{~Hz}$ sampling to study the "twilight zone" around clouds where strong aerosol-cloud interactions are taking place.

Part Three involves continuing our cloud optical depth and cloud fraction retrieval research with ARM's 2NFOV instrument by, first, analyzing its data from the AMF-COPS/CLOWD deployment, and second, making our algorithms part of ARM's operational data processing. 


\title{
Accomplishments: Highlights and publication list
}

\author{
References to cited papers are given in []
}

(1) Pioneering work on cloud property retrievals [5] has attracted favorable notice well within and outside the ARM community. NASA AERONET has adopted our methods and operated sunphotometers in "cloud mode", promising the first worldwide observation of cloud optical depth from the ground (Fig. A1). We tested cloud property retrievals at the ARM Oklahoma site for a variety of situations. For overcast cases, 1.5-min average cloud-mode optical depth retrievals agreed to better than 15\% with those from MFRSR. For broken clouds, our retrievals could capture the rapid variations revealed by the MWR. A three-year climatology of cloud-mode retrievals agreed well with cloud radar retrievals in both seasonal variation and occurrence distribution.
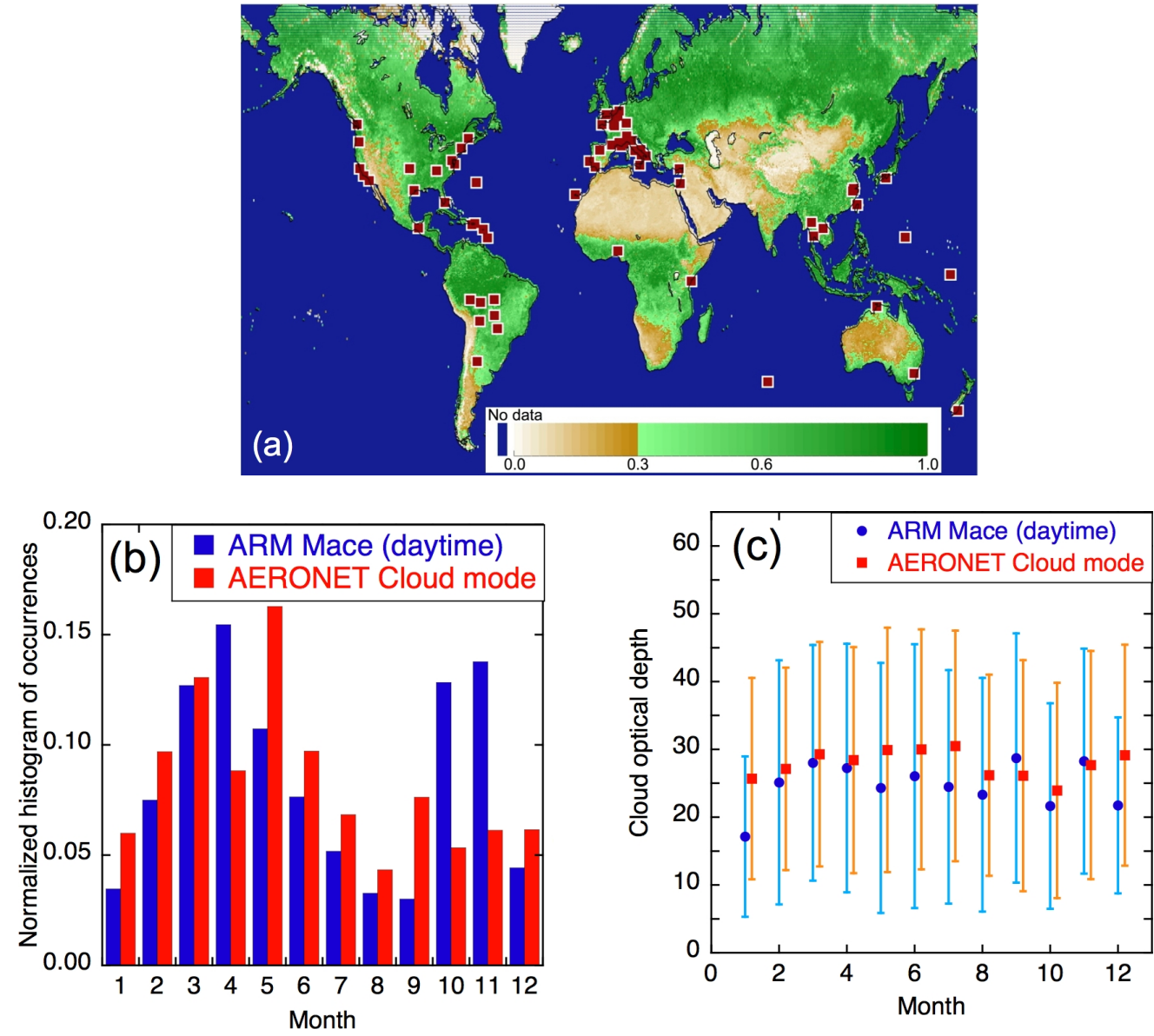

Fig. A1. (a) Potential cloud mode site locations in AERONET. (b) Normalized histogram of occurrence for overhead cloudiness at the ARM SGP. Blue bars represent occurrences of Mace's retrievals during years 2002-2004, while red bars represent occurrences of AERONET retrievals during Nov 2004 - Jun 2008. (c) Monthly average cloud optical depth with one standard deviation. 
(2) Lidar solar background for cloud optical depth retrievals [1]. It is widely believed that lidar cloud retrievals are limited to optically thin clouds. Indeed, laser beams emitted from space-borne lidars, can only penetrate clouds to a limit of a few optical depths. As a result, only optical depths of thinner clouds are retrieved from the reflected lidar signal. In Paper 6 we made a comprehensive study of possible retrievals of optical depth of thick clouds using solar background light and treating the ICESat/GLAS telescope as a simple solar radiometer. Cloud optical depth is retrieved from the calibrated solar background signal using a onechannel retrieval. Comparison with cloud optical depth retrieved from GOES during ICESat overpasses shows that the average difference between the two retrievals is about $25 \%$. Thus now cloud optical depth can be retrieved from ICESat for all clouds: from thin transparent to thick opaque. This paper is a continuation of our earlier study of the solar background of ARM MPLs.

(3) Cloud optical depth retrievals for studying aerosol-cloud interactions [3]. In Paper 3 we examined aerosol-cloud interactions under coastal stratiform clouds, using data from the ARM Mobile Facility deployment at Point Reyes, CA in 2005. We have characterized and found that aerosol-cloud interactions varied depending on the environmental conditions and observational approaches, such as 1) the assumption of constant cloud liquid water path (LWP), 2) the relative value of cloud LWP, 3) methods for retrieving cloud drop number concentration, 4) aerosol size distribution, 5) updraft velocity, and 6) the scale and resolution of observations. We have also actively participated in the CLOWD intercomparison, a major ARM activity, using data collected at SGP with 1NFOV and MPL solar background. CLOWD stands for Clouds with Low Optical (Water) Depth; it is a subgroup in ARM Radiative Properties Working Group.

(4) ARM SWS data are used to study cloudy-clear transition zone [2]. To the naked eye, clouds appear to have sharp boundaries. But cloud boundaries are actually somewhat fuzzy. Fuzzy cloud boundaries create major headaches for studies of aerosol indirect effect and aerosol radiative forcing - especially when, as with most satellite instruments, spatial resolution is too poor to resolve the transition zone. Recently, one-sec-resolution data from the shortwave spectrometer (SWS) provide a unique opportunity to analyze the transition zone. In Fig. A2 we demonstrated a remarkable linear relationship in the transition zone between the sum and difference of radiances at 870 and $1640 \mathrm{~nm}$ wavelengths. The intercept of the relationship is mostly determined by aerosol optical depth, while the slope is mostly determined by cloud droplet size. This linearity could be predicted from simple theoretical considerations and furthermore supported the inhomogeneous mixing hypothesis. 


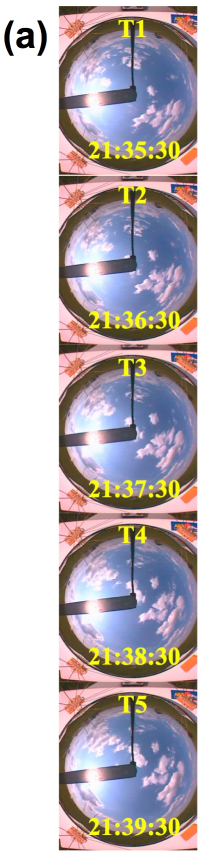

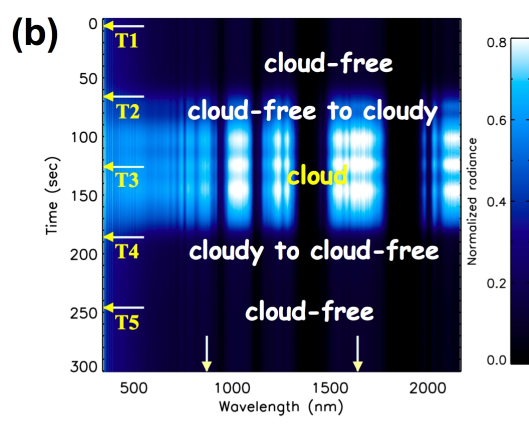

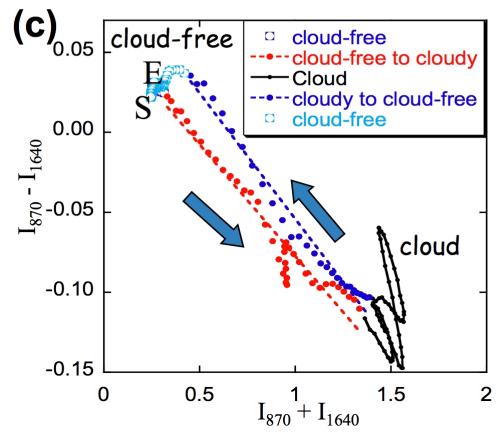

Fig. A2. (a) Total sky images on 18 May 2007, and (b) plot of SWS normalized zenith radiances. In (b), arrows pointed at the time axis correspond to the times of the images shown in (a), while arrows pointed at the wavelength axis correspond to 870 and $1640 \mathrm{~nm}$. (c) is the plot of radiance difference vs sum at 870 and $1640 \mathrm{~nm}$. Letters $S$ and $E$ indicate the start and end of the time series. Two arrows show the flow of time evolution. A remarkable linear relationship is found in the transition zone.

(5) A spectral invariance behavior [4,7] was found and simulated between ratios of zenith radiance spectra during the transition from cloudy to cloud-free. This behavior suggests that the spectral signature of the transition zone is a linear mixture between the two extremes (definitely cloudy and definitely clear). The weighting function of the linear mixture is a wavelengthindependent characteristic of the transition zone. An important result of these discoveries is that high temporal resolution radiance measurements in the clear-to-cloud transition zone can be well approximated by lower temporal resolution measurements plus linear interpolation.
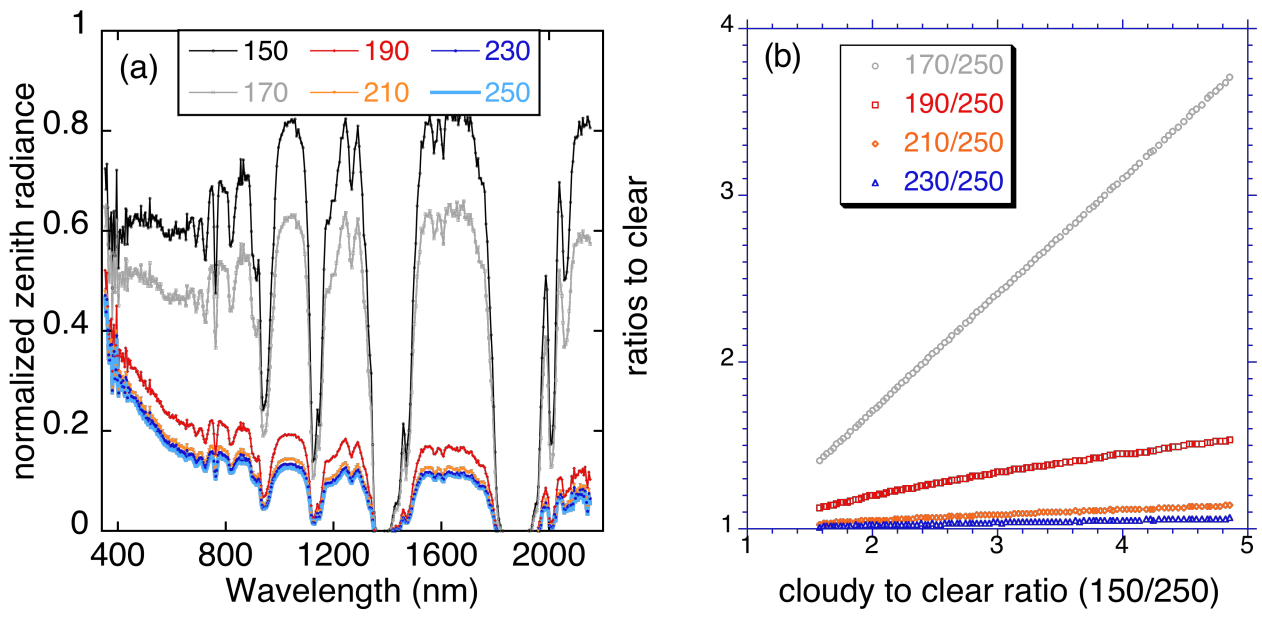

Fig. A3. (a) Normalized SWS zenith radiance spectrum measured on 18 May 2007 from $150 \mathrm{~s}$ (cloudy) to $250 \mathrm{~s}$ (clear) with 20s interval. (b) Ratios of zenith radiance at wavelengths from 350 to $1800 \mathrm{~nm}$, excluding water vapor absorption bands. 


\section{(6) Understanding atmospheric and cloud changes in boundary layers in a doubled $\mathrm{CO}_{2}$}

climate [6]. In Paper 6, we used an idealized equilibrium model to explore the coupling of the energy, water, and carbon cycles over land in mid-latitudes and to understand how surface fluxes, the boundary-layer equilibrium, and the cloud cover change for a warmer, doubled $\mathrm{CO}_{2}$ climate. We have found that the doubling of $\mathrm{CO} 2$ decreases the canopy conductance, reduces transpiration, increases the surface sensible heat flux, and then gives a much warmer and deeper mixing layer with a lower surface humidity. There is a corresponding 15\% drop of relative humidity at the base of mixing layer and a $\sim 60 \mathrm{hPa}$ rise of cloud base. In addition, equilibrium cloud is sensitive to temperature, subsidence, and $\mathrm{CO}_{2}$; so changes of mean subsidence will play a critical role in determining changes in cloud cover in a warmer, high $\mathrm{CO}_{2}$ climate.

\section{Publications (June 2008- August 2010)}

(Members of our science team are in bold)

[1] Yang Y., A. Marshak, J. C. Chiu, W.J. Wiscombe, S. P. Palm, A. B. Davis, D. A. Spangenberg, L. Nguyen, J.D. Spinhirne, and P. Minnis, 2008: Retrievals of cloud optical depth from the Geoscience Laser Altimeter System (GLAS) by calibration of solar background signal. J. Atmos. Sci., 65, 3513-3527, doi: 10.1175/2008JAS2744.1

[2] Chiu, J. C., A. Marshak, Y. Knyazikhin, P. Pilewskie, and W. J. Wiscombe, 2009: Physical interpretation of the spectral radiative signatures in the transition zone between cloud-free and cloudy regions. Atmos. Chem. Phys., 9, 1419-1430.

[3] McComiskey, A., G. Feingold, A. S. Frisch, D. Turner, M. Miller, J. C. Chiu, Q. Min, and J. Ogren, 2009: An assessment of aerosol-cloud interactions in marine stratus clouds based on surface remote sensing. J. Geophys. Res., 114, D09203, doi:10.1029/2008JD011006.

[4] Marshak, A., Y. Knyazikhin, C. Chiu, and W. Wiscombe, 2009: Spectral invariant behavior of zenith radiance around cloud edges observed by ARM SWS. Geoph. Res. Lett., 36, L16802, doi:10.1029/2009GL039366.

[5] Chiu, J. C., C.-H. Huang, A. Marshak, I. Slutsker, D. M. Giles, B. N. Holben, Y. Knyazikhin, and W.J. Wiscombe, 2010: Cloud optical depth retrievals from the Aerosol Robotic Network (AERONET) cloud mode observations. J. Geophys. Res., J. Geophys. Res., 115, D14202, doi:10.1029/2009JD013121.

[6] Betts, A. K. and J. C. Chiu, 2010: Idealized model for changes in equilibrium temperature, mixed layer depth and boundary layer cloud over land in a doubled CO2 climate. J. Geophys. Res., 115, D19108, doi:10.1029/2009JD012888.

[7] Chiu, J. C., A. Marshak, Y. Knyazikhin, and W.J. Wiscombe, 2010: Spectral invariant behavior of zenith radiance around cloud edges simulated by radiative transfer. Atmos. Chem. Phys., 10, 1129511303. 